\title{
Can patient choice shape organisational behaviour to provide patients with what they want?
}

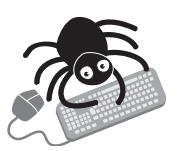

Please visit the QSHC website (http://www.qshc.com) for links to these articles - many to full text.

"Choice mechanisms enhance equity by exerting pressure on low quality or incompetent providers" Tony Blair, 23 January 2003

Recently published papers illuminate some tensions between differing conceptions of what the extension of patient choice will mean for the UK National Health Service (NHS). While some promote a consumerist model, others favour a more personally engaging interpretation. This contrast is evident in two consultation documents on choice issued by the government. The first (Payment by results consultation: preparing for 2005, available at http:// www.doh.gov.uk/nhsfinancialreforms/) is concerned with financial flows and the setting up of a system by which money follows the patient, and the second (Fair for all, personal to you: a consultation on choice, responsiveness and equity, available at hitp:// www.doh.gov.uk/choiceconsultation// more with patient experience, asking questions about the choices patients want and the information they need to exercise them. The following papers are written across the spectrum of choice and offer insight for the NHS in shaping choice in practice.

\section{A push to give the public choice of provider in the UK public sector $>$ In 2001, Prime Minister} Tony Blair said choice "should be a central principle for reform". From 2005 it will come to the NHS in the form of patients being offered a choice of secondary provider for some elective treatments. In this context "choice" means "a set of institutionalised arrangements that provide opportunities to make decisions expressing preferences between a defined menu of options". The term is exclusively individual. This form of choice has been introduced in other sectors-a nursery school voucher scheme introduced in 1996 (but abandoned the following year) and choice of secondary school introduced in 1988. A paper in the Journal of Social Policy examines the goals, experience, and unanticipated side effects of choice within each.

It is difficult to establish whether initiatives have been successful because "there are few objective, comprehensive, detailed and rigorous published evaluations of the implementation of consumer choice schemes against their objectives". Writers have stressed the importance of local experience and "therefore the difficulties of generalising". However, some lessons can be learned. First, policy that aims to improve local responsiveness can sometimes unwittingly be crowded out by more centralist concerns. The 1998 school reforms that sought to catalyse local innovation through choice of provider, for example, coincided with another to introduce a national curriculum.

Choice in schools has been written about most widely. Research has reported positive reaction from the majority of parents of young children outside London and may have contributed to "keeping a significant proportion of the middle class within the system, except in London and the south east". Experience has also shown that market mechanisms do not operate as theory intended-for example, "the fact that 'special measures' [do] not always quickly either turn failing schools around or effect their exit"

Similar to the argument that hospitals will become more responsive as a result of funding following patient preferences, it was argued that school choice- and money following the studentwould discipline schools to improve their productivity. However, "when significant proportions of consumers do not choose in this way choice-or at least choice alone-may not bring about efficiency". A particular problem has been polarisation, which can be defined as the situation in which the market separates into "a 'sink' sub-sector of underperforming suppliers located in disadvantaged areas unable to attract good staff and for which there are falling levels of consumer demand and no competition between consumers for access, and an 'elite' sub-sector of high performing suppliers located in wealthy, leafy areas able to attract good staff, with high levels of applications, where there is congestion, and where in effect the suppliers choose the consumers".

Because the nursery vouchers scheme was terminated so quickly after being introduced, rather little can be said about its success. The 1997 Labour government were of the view that "its transaction costs were excessive in proportion to the size of the scheme and any benefits it was likely to have". Two polls in 1996 showed mixed results. However, the House of Commons Education and Employment Committee's (1997) report suggested the scheme had inadvertently "led to a reduction of parental choice". There were fewer providers to choose between as the "bulk of the voucher income went to schools for reception classes, not least because the more popular schools used reception class attendance as an admission criterion for subsequent primary education. This caused some private providers to close."

The lesson for others is to beware of "less fortunate consequences of consumer choice programmes that should probably fairly be regarded as unintended by government".

A Perri G. Giving consumers of British public services more choice: what can be learned from recent history? J Social Policy 2003;32:239-70

\section{Economic analyses of the implications of consumer choice $>$ The King's Fund lan independent} charitable foundation whose goal is to improve health, especially in London) open their analysis of patient choice by setting out some tensions faced by promoting the concept in the NHS. The core issue is "an irreconcilable conflict-in the context of a fixed health care budget-between allowing individual patients unconstrained choice of treatments that are free at the point of consumption and the allocation of resources in a cost effective manner"

Nonetheless, this is an irresistible trend to which the NHS must respond and follows from the growth of consumerism, wider availability of information, preferences for alternative treatments, developments in clinical knowledge, and the rise in the use of the private sector for elective procedures. Two main arguments are employed in the promotion of choice:

- when people can take their money elsewhere, they put pressure on producers to be efficient and to develop new products;

- when people have a range of alternatives, they can choose the mixture of goods that best meets their preferences.

The authors note it is difficult to oppose choice: "Who could argue against the desirability of allowing patients more say in decisions concerning their health?" But, equally, health care is not a straightforward consumer good. It is difficult for patients to judge the quality of care: choices made may not be informed, out of step with the collective voice, and it may not be efficient to develop an infrastructure for choice where one does not exist, for example, outside metropolitan areas. The authors worry that "hospitals that lose patients to other establishments because of patient choice could face a spiral of financial decline. Such hospitals might then have difficulty in responding to the 'market signals' of patient choice, resulting in poorer services for those patients remaining with their 'home' hospital."

The authors note that "all systems restrict choices" on financial and ethical grounds. Even in America where choice is a national 
value, HMOs limit range and provision of services. There are also doubts that "choice" means the same thing to everyone and that policy conceptions are geared towards efficiency savings and improved management of the system. Voice can sometimes "partly be seen as a substitute for patient choice, in that it provides patients with a voice to ask for the services they want". But patient choice is not always a substitute for patient involvement. Even in its present form, the NHS has the potential to offer patients much greater choice than it currently does ... "effective choice is more than simply knowing which hospital has the shortest waiting time".

$\Delta$ Appleby J, Harrison A, Devlin N. What is the real cost of more patient choice? London: King's Fund. (The paper was published 5 June 2003 and can be downloaded free from http://www.kingsfund.org.uk/pdf/PatientChoice.pdf)

Many commentators in the UK worry that patient choice will usher in an increasing role for the private sector in health care and that this will mean the irrecoverable erosion of the NHS. They fear this because of the constraints on choice within public systems. Journal articles outlining the American experience provide constant reminders of the unpalatable extremes of consumerism.

Why more choice is not always better The fastest growing (post-managed care) initiative in America is the "consumer driven health plan". People can "designate individual or customized benefit packages and providers and pay any cost beyond a fixed contribution by their employer". It is estimated these plans "could account for up to $50 \%$ of the market within 5 years". They "are being marketed as the revolution that will solve the perennial problem(s) of increasing costs and decreasing coverage inherent in the health care delivery system in America ... consumers will have control of their own health care decisions - they will have 'freedom of choice'. This approach capitalises on the opportunity created by managed care backlash, in which lack of choice is one of the most frequent complaints."

"Rational or purposeful choice by individual agents is the foundation upon which modern neoclassical economics is built. What is often implied is that a system of economic freedom embodied by individual freedom of choice is what [US economist Milton Friedman described as] 'a necessary condition for political freedom'. Hence, giving people economic levers is tantamount to their shaping the service. Unfortunately, that freedom often turns out to be an illusion of choice since many assumptions made about human behaviour in theoretical models do not exist in actual exchanges."

The author gives a number of reasons why consumer choice and health care are ill related:

- Health outcomes are dependent upon an initial endowment of genetic make up and predisposition to certain illnesses.

- Health care is uncertain.

- Consumers cannot have perfect knowledge.

- A major aim of health services ("social welfare") is based on aggregate individual utilities-consumer thinking rather than collective and strategic logic.

- An argument for choice is that consumers will get more for their money if they get to spend it-an ethical position that has been interpreted as "the consumers' right to make their own mistakes".

- The choices an individual makes when well are not the choices made when that person is ill-economic forces are not always the most responsive.

- Promising choice to consumers does not mean that they will have choice among all possible options. What it means is that they will have choice among some given range of options that has been selected for them.

- What a person wants is what he/she is familiar and comfortable with.

The paper concludes: "Words can be deceptive, especially when they are used to mislead. The public should be sceptical of consumer driven plans that refer to choice. The plans are designed to cut costs for employers but are also intended to further an agenda-making provision of medical services a commodity, which includes user fees for health care. Having more choice is not always better; it does not always follow the assumptions of the underlying theory; and it does not always play out in practice as the theory would suggest."
A Bownds L. Consumer-driven health plans: more choice is not always better. J Econ Issues 2003;XXXVII:425-32

Choice as empowerment $>$ An economic discussion of choice in health makes depressing reading for many. But choice does not necessarily have to be consumerist in orientation. The two papers that follow look at the experience of patient involvement in redesigning services and the ingredients for "a successful evidence-based patient choice consultation". Both are concerned with cancer care and are written by British authors.

Can users influence the design of care? This paper presents initial findings from a 3 year study of user involvement in cancer services using both case study and survey data. It examines cancer services in a part of south-west England and considers the following areas: definition of user, aim of involvement, level of involvement, method of involvement, duration of involvement, action/outcomes, and organisational support for user involvement.

The most common way for NHS organisations to involve users is through questionnaires. Some have used focus groups, but many see public meetings and complaints procedures as adequate mechanisms for involvement. In this cultural context, users themselves fear initiatives pay "purely lip service" to the notion.

The researchers followed the development of a focus group in a particular hospital. Patients were sent letters inviting them to attend a focus group at the hospital and to bring a carer or friend if they liked. "Those users who participated were keen to share their views and appreciated the opportunity to reflect on their experiences in a way that would improve cancer services". Focus group discussions were recorded and transcribed and the manager of cancer services went through the document to "try and pull together what's in it and write it under different headings sort of thing". The manager circulated reports to different groups, including "relevant consultants".

"During the first 18 months of the programme 86 patients and 46 carers were involved ... providing benefits. The voluntary organisations ... gained resources and training for members. More important, perhaps, they played a pivotal role in promoting the views of the users they claim to represent."

However, the process also raised a couple of problematic issues:

- Feedback was given in an annual letter from the group facilitator "citing particular instances of changes". A patient who had participated in one of the focus groups was very upset by the annual feedback letter as it made no reference to the issues raised by her group. "None of it was to do with breast cancer ... nothing was mentioned about the wards being dirty and the nursing staff which was really key".

- Confidentiality became an issue "where individual health professionals were named and blamed". Staff felt the organisation made "an assumption that the user reports were accurate and that the fault must lie with the health professional". Reports from focus groups were handled through complaints procedures and "used for managerial purposes". Staff developed "an increased wariness around patients and a loss of faith in user involvement".

A key problem in promoting user involvement is the lack of clear understanding of its purpose. "There was little evidence of any specific agenda for involving users in cancer services that was distinct from either research or accreditation exercises". "Much of what is currently termed user involvement is in fact the collection of data from users or is part of specific projects rather than empowering users to make choices about the organisation and delivery of cancer services". The researchers say, "the absence of any common definition of user involvement or its purpose underlines the limited trust between the different actors in the system and highlights the potentially negative impact of [attempts to modernise] the health service".

A Tritter JQ, Barley V, Daykin N, et al. Divided care and the Third Way: user involvement in statutory and voluntary sector cancer services. Sociol Health Illn 2003;25:429-56

Informing decision making - The term "evidence based patient choice" was first described by Tony Hope (one of the authors) in 1996 as the merging together of two important movements in western health care-namely, evidence-based 
medicine and patient-centred care. The joining of two concepts allows one to counter the weaknesses of the other. In the biomedical approach "the individual qualities, needs and preferences of patients have tended to be neglected as relevant factors in the decision making process". Equally, "providing patients with evidence-based knowledge should enhance their power and aid the development of an increasingly effective patient-centred health care system". The onus in this approach is the arming of patients and doctors with high quality knowledge and drawing on treatment to influence the system.

The authors note the existence of different preferences. A study of women diagnosed with breast cancer "showed that $20 \%$ wanted an active role in deciding their treatment, $28 \%$ preferred a joint decision, and just over half (52\%) wanted their surgeon to decide for them" ${ }^{\prime \prime}$. The lack of information may influence this balance and more informed patients might be less passive.

To explore what an ideal patient choice consultation would look like, the researchers interviewed 11 primary care physicians (three women), 10 hospital consultants (four women), 11 academics (four part time primary care physicians, seven women), five nurse practitioners (all women), and eight lay people (one man). "Overall, participants had a clear understanding of the theoretical principles behind evidence-based patient choice but, perhaps unsurprisingly, were less clear about the specific processes that might be involved to achieve it during a medical consultation."

There are two important elements to the ideal patient choice consultation: information and decision making. It was thought important for doctors to be "well informed and appraised of the latest available medical evidence". "Related to this, a need was identified for doctors to be trained in computerised data retrieval and to attend training courses on how to practise evidence-based medicine. It was important for patients to have access to good sources of evidence. There was a feeling, particularly from academics and lay people, that the quality of written patient information and internet health sites was generally poor and required some form of quality control. Patients should expect to be informed about the nature of their illnesses/problems and be directed by the doctor to other sources of information relevant to the diagnosis. The importance of honesty was emphasised mostly by academics and lay people in the context of options .... and the description of risk and side effects associated with each treatment alternative."

In aiding patient decision making, "the most frequently mentioned skill was the ability to listen ... to enable assessment of the language that patients use in order to pitch information levels". In addition, "doctors should acknowledge that patients bring knowledge to the consultation-they have life experiences". Patients should be encouraged to have time to "take in" information and ponder their choices. Doctors tended to "frown upon providing all the options and then expecting patients to decide which was best for them". The majority felt that doctors should advise patients. "Lay people tended to state that doctors should give an opinion as to which treatment would be most appropriate, but the patient should have the right to reject this."

The major obstacle to patient choice consultations is having enough time. One GP said: "Ideally consultation length should not be an issue as patients need time to talk and ask questions about options". A layperson suggested this might be countered if "patients could spend a little time preparing for the consultation beforehand". A key challenge is to develop information to enable patients to make choices. "Recent studies of patient information materials and internet health information have found that few sources meet patients' information needs in terms of presenting information about the range of relevant treatment options, and providing a nonbiased, evidence-based view of the effectiveness of each treatment."

In analysing the responses given in interviews, the researchers note that "participants tended to compartmentalise their responses so that these related either to the patient centred elements .... or the evidence-based medicine components". The authors argue that "the majority of patients have a desire for more information about their illness and treatment options, but only a small number appear to express a preference to participate in treatment decisions". Patients want to make choices in close proximity with health professionals: patients need knowledge to take a meaningful part; professionals need time and organisational support to shape services based on best treatments and patient preferences to opt between them.
A Ford S, Schofield T, Hope T. What are the ingredients for a successful evidencebased patient choice consultation? A qualitative study. Soc Sci Med 2003;56:589602

\section{How would patients choose to relate to health service providers? With such different} conceptions of choice and a lack of evidence about its experience in practice, all the talk is theoretical or hypothetical. Perhaps a better starting point is to consider what kind of relationships patients want with the health service.

Choice of provider Estonia is the unlikely source of a first insight into the preferred relationship of patients with the health system. The background to the study is important.

Following fundamental changes in society in the countries of Central and Eastern Europe, remarkable reforms in health care were undertaken at the beginning of the 1990s. Most of these countries changed from state budget funded centralized systems to insurance based liberal fee for service payment systems. Estonia attempted "to move from a highly specialised medical provider to a primary care orientated system". "Every person was expected to choose his or her family doctor ... they could register personally while contacting the doctor at his/her office ... or opt to be included in the list [of the] local polyclinic."

The researchers wanted "to compare satisfaction with primary health care [amongst] those who chose their doctor on their own initiative and those who [chose...] a local polyclinic". They interviewed 997 people aged 16-74 years using "a precategorized questionnaire which was worked out in cooperation with ... the University of Tartu and the market research company EMOR"

"Patients who had registered with a personal doctor were more likely to be women and persons who considered their health status poorer compared with others." Less than half the population of the capital registered with a doctor personally against three quarters of the rest of the urban population. $68 \%$ of the sample had registered with a named individual.

Those who chose a doctor were more satisfied on every dimension. The authors found "most Estonian citizens wish to receive care from a regular personal physician who knows them and is familiar with their problems". Those who see themselves as having particular health needs prefer to find a doctor they can maintain a relationship with. "Interpersonal trust is a prerequisite of many aspects of effective health care, not only of patients' acceptance of prescribed therapy or investigations, but also of organizational factors." People's opinion "about several organizational and interpersonal aspects of care was more favourable when the chosen doctor had a solo practice rather than worked in a big polyclinic". "The sense of responsibility of a physician for his/her patients is [thought] stronger in a personal doctor system."

"The most important conclusion of our study is that there is association between personal choice and patient satisfaction." It is interesting how different the discussion becomes depending upon whether choice relates to the choice of the individual or organisational provider.

A Kalda R, Polluste K, Lember M. Patient satisfaction with care is associated with personal choice of physician. Health Policy 2003;64:55-72

Changing patient-professional relationships The changing public perception of patient-doctor relationships is the subject of a paper that draws on data collected in the US, UK, Canada, Germany, South Africa and Japan from 2506 telephone interviews conducted with patients and 1201 with physicians using a random digit dialling (RDD) methodology.

In all countries "the physician was viewed by patients as the dominant source of health information. In addition, patients had far greater trust in the accuracy of information coming from physicians versus other sources ... and were far more likely to change their health behaviour based on information from a physician compared to other sources." "Patients in all countries agree that authoritarian paternalistic relationships are relatively uncommon today" and see a continuing trend toward more partnership based relationships. (The following proportions feel their relationship with physicians could be characterised as paternalistic: UK 20\%, US 17\%, South Africa 16\%, Canada 13\%, Germany 13\%, Japan 12\%.) 
One of the interesting insights from the research may be thought obvious but is nevertheless important-people want different things. To the question: "In managing risk related decisions, which do you prefer?", $6 \%$ of UK citizens wanted the doctor to take total responsibility, 36\% to provide options and tell you what to do, and $57 \%$ to provide options and leave decisions to you. A further $1 \%$ could not be sure which they wanted. (The paper contains full tables for each country and can be accessed from the link given belowthe focus here is on the UK.)

All patients and doctors in the UK were asked to rate questions posed within two dimensions:

- "Humanistic" featuring the following elements: compassion, trust, understanding, patience, listening; and

- "Access" to treatment, doctor, patients, time with doctor, appointment scheduling.

$54 \%$ of patients think they do not spend enough time with doctors ( $49 \%$ of doctors agree). In identifying potential for improvement, doctors and patients have different expectations, with those of the patients being higher: $91 \%$ of humanistic elements should be met and $89 \%$ of access goals. "Patients foresee an average $27 \%$ potential for improvement in the humanistic domain and $40 \%$ in the access while physicians see only the opportunity for a $10 \%$ and a $14 \%$ improvement in humanistic and access domains respectively." "Physician aspirations [are] tempered by their perceptions of what is realistic in light of the available resources and the level of function or dysfunction of their health delivery system."

Given this view, the introduction of choice may have considerable consequences for the relationships between patients and primary care physicians. The danger is that doctors' level of pessimism may contrast with high expectations from patients who then may "react negatively to the physician whose 'ideal' has gradually descended to what is "possible'". If high expectations are not met, "patients are left to logically acknowledge the presence of one of two realitieseither 'my physician doesn't care about $\mathrm{me}^{\prime}$ or 'my physician is powerless to advocate for me'. Either way, the common result is to draw the patient away from the relationship-as he/she acknowledges: 'I now must fend for myself'-and to draw the physician away ... mired in helplessness and hopelessness. The net effect is that patients and physicians who are natural allies are gradually repositioned as adversaries."

While this study clearly reveals that the evolution of the patientphysician relationship is a worldwide phenomenon, the speed, readiness, and stresses vary somewhat from culture to culture. The NHS may not now face unconstrained consumerism from the public but its injection, in the form of patient choice initiatives, must take into account the potential implications for patient-professional relationships. If choice is promised, it must be available within the system.

A Magee M. Relationship-based health care in the United States, United Kingdom, Canada, Germany, South Africa and Japan: a comparative study of patient and physician perceptions worldwide. Paper presented at the World Medical Association, 11 September 2003 (available free at http://www.wma. net/e/press/pdf/2003_15.pdf).

\section{Conclusions} economic theories of responsiveness. Is choice about enhancing efficiency, increasing capacity and diversity of provider or is it more about redefining service encounters to allow patients to shape a relationship of their own choosing? Is it consumerist or empowering in nature? A tension exists between these alternative perspectives and, if choice is to become a meaningful and positive force in the UK health system, these different positions need to be negotiated.

T Smith

Senior Policy Analyst, Health Policy and Economic Research Unit, BMA House, Tavistock Square, London WC1H 9JR, UK tsmith@bma.org.uk

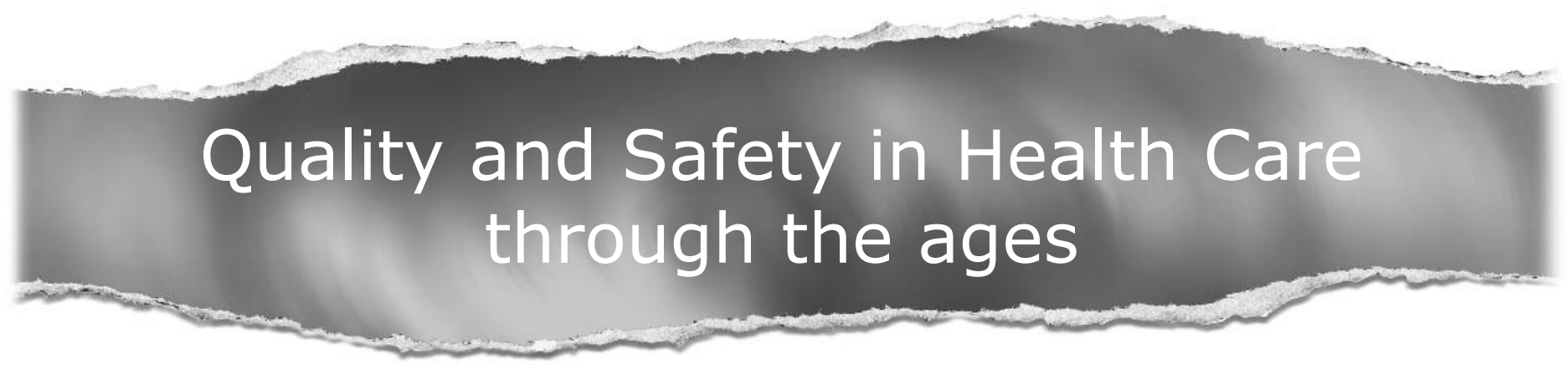

\section{Browse the Archive}

Quality and Safety in Health Care online has an archive of content dating back to 1992. Full text from January 2000; abstracts from 1992; table of contents from 1992.

\section{www.qshc.com}

